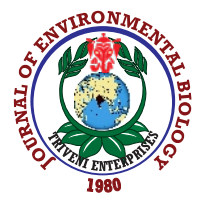

\title{
Natural occurrence and diagnosis of yellow leaf disease affecting sugarcane genotypes under tropical and sub-tropical conditions in India
}

\author{
A. Kumar ${ }^{1,2}$, S.K. Holkar ${ }^{1 *}$, R. Singh ${ }^{2}$ and J. Singh ${ }^{3}$ \\ ${ }^{1}$ ICAR - Indian Institute of Sugarcane Research, Biological Control Centre, Pravaranagar-413712, India \\ ${ }^{2}$ Amity Institute of Biotechnology, Amity University, Uttar Pradesh Campus, Lucknow - 226 028, India \\ ${ }^{3}$ Uttar Pradesh Council of Sugarcane Research, Shahjahanpur - 242001, India \\ *Corresponding Author Email : somnathbhu@gmail.com
}

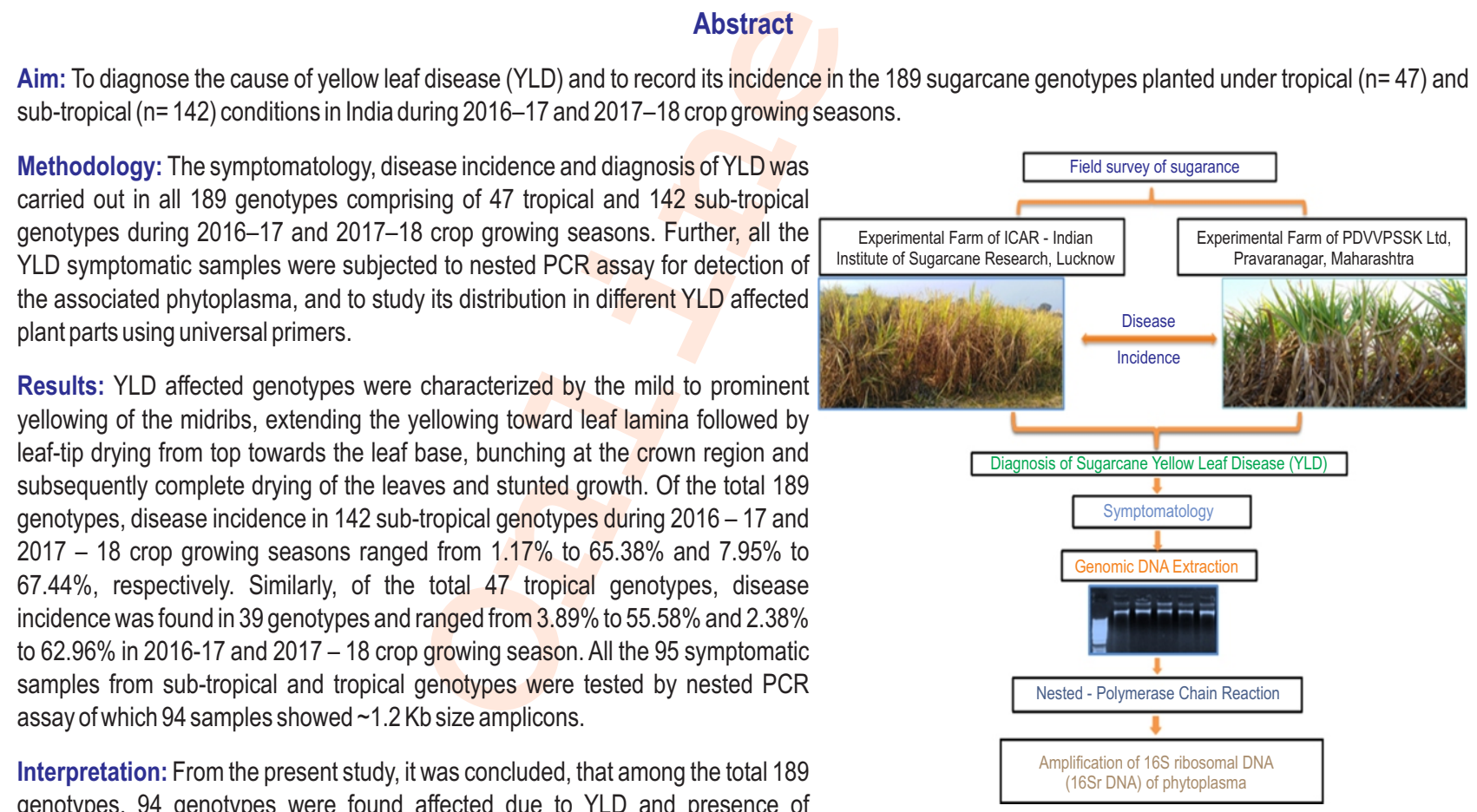
phytoplasma in these genotypes were diagnosed. Remaining 95 genotypes which were found apparently healthy would be a good source of resistance and can be further involved for the development of YLD resistant sugarcane progenies in India.

Key words: Disease incidence, Nested PCR, Sugarcane yellows phytoplasma, Yellow leaf disease

How to cite : Kumar, A., S.K. Holkar, R. Singh and J. Singh: Natural occurrence and diagnosis of yellow leaf disease affecting sugarcane genotypes under tropical and sub-tropical conditions in India. J. Environ. Biol., 41, 1511-1520 (2020). 


\section{Introduction}

Sugarcane (Saccharum hybrid) is one of the most important cash crops of India. It belongs to the genus Saccharum and family Poaceae. Sugarcane is a long duration crop and needs around 12-18 months to mature, based upon the geographical conditions i.e., tropical and sub-tropical. It requires hot and humid climate with average temperature of $21^{\circ} \mathrm{C}-27^{\circ} \mathrm{C}$ and $75 \mathrm{~cm}-150$ $\mathrm{cm}$ rainfall. In tropical conditions, three planting methods are recommended because of conducive weather for sugarcane growth and development. Three planting methods viz., seasonal (crop duration 14-15 months), pre-seasonal (12 months) and kharif/ adsali (18 months). Whereas, under subtropical conditions sugarcane faces the high temperature during summer and low temperature during winter season therefore, mainly two planting times are recommended in subtropics i.e., autumn and spring plantings. Autumn planting is done during October and delay in autumn planting affects cane germination and yield whereas, spring planting is done in February - March to avoid heat stress during April-May.

Worldwide, sugarcane is known to infect by many fungal, bacterial, and viral diseases and are the major constraints in its production and productivity. Besides these fungal, bacterial and viral diseases, phytoplasma are one of the major constraints in sugarcane production including Sugarcane white leaf phytoplasma (SCWLP) (Sdoodee, 2001, Rao et al., 2008, Soufi et al., 2013), Sugarcane grassy shoot phytoplasma (SCGSP) (Singh et al., 2002, Rao et al., 2008) and Sugarcane yellows phytoplasma (SCYP) (Cronje et al., 1998; Arocha et al., 2000; Gaur et al., 2008; Kumar et al., 2015). Of which SCYP is one of the serious pathogens causing severe reduction in cane growth and yield contributing parameters (Cronje et al., 1998). Association of phytoplasma with YLD was detected from different sugarcane growing countries including, Australia, Cuba and Mauritius (Cronje et al., 1998; Arocha et al., 1999; Aljanabi et al., 2001). Moreover, latent infections of $16 \mathrm{Srl}$ and $16 \mathrm{SrXI}$ subgroups of phytoplasma have also been reported from asymptomatic sugarcane cultivars in Hawaii (Soufi and Komor, 2014). Subsequently, association of 'Candidatus phytoplasma asteris' subgroup (16Sr I-B) was reported from Brazil, Egypt and India (Silva et al., 2009; Elsayed and Boulila 2014; Kumar et al., 2015) and white leaf phytoplasma in Thailand (Soufi et al., 2013).

Worldwide, first evidence of YLD was reported in Hawaii in sugarcane (S. officinarum) cv. H 65-7052 (Schenck,1990). Subsequently, identical visual symptoms were also reported in Florida (Comstock et al., 1994). Since then, symptoms of YLD have been recorded and diagnosed in more than 20 countries including Australia, Brazil, Cuba, Mauritius, Reunion, South Africa and the USA (Bailey et al., 1996; Cronje et al., 1998). YLD, earlier known as yellow leaf syndrome (YLS) is caused by SCYP and Sugarcane yellow leaf virus (SCYLV). In India, YLD is caused by SCYLV (Viswanathan et al., 1999, Rao et al., 2000, 2001, Viswanathan et al., 2002). Later, Gaur et al. (2008) for the first time reported the association of SCYP with YLD in India.
Recently, from our earlier study, first report of 'Ca. phytoplasma asteris' (subgroup: 16Srl-B) was detected in the two YLD affected sugarcane varieties i.e., CoLk94184 and CoSe 92423 by Kumar et al. (2015) and in other four popular sugarcane varieties by Kumar et al. (2018). Further, disease incidence and distribution of phytoplasma in large number of genotypes and identification of resistant sources for YLD have not yet been well studied under sub-tropical conditions. Therefore, in the present study, systematic and regular studies were conducted to ascertain the prevalence of YLD in different sugarcane genotypes and detected the presence of pathogen in different plant parts during 2016 - 17 and 2017 - 18 crop growing seasons.

The primary natural transmission of phytoplasma is known to occur by vegetative propagation and secondary by insect-vectors from infected to healthy sugarcane crop. Phloemfeeding planthoppers (family: Cicadellidae) are the most effective insect-vectors for the transmission of phytoplasma. (Maixner and Reinert, 1999; Gatineau et al., 2001). SCYP belongs to Aster yellows phytoplasma16Srl-A subgroup and transmitted naturally by delphacid planthoppers (Saccharosydne sachharivora) (Arocha et al., 2005). In India, association of $16 \mathrm{SrXII}$ group of phytoplasma was detected in the YLD affected sugarcane genotypes (Gaur et al., 2008; Rao et al., 2012). Insect transmission of phytoplasma causing grassy shoot disease (GSD) has been studied (Singh et al., 2002; Srivastava et al., 2006) but information on insect transmission of SCYP causing YLD is meagre. Since last two decades, YLD has become a serious concern for researchers and sugarcane growers, and this has generated keen interest to understand the disease epidemiology and development of the better management tactics. Further, screening of sugarcane genotypes against YLD would be future line of research. Therefore, the present study was undertaken to detect the associated pathogen in large number of sugarcane genotypes and its prevalence in these genotypes in the tropical and sub-tropical conditions of India.

\section{Materials and Methods}

Planting of sugarcane genotypes: A total of 189 sugarcane genotypes were planted for evaluating of YLD under field conditions, of which 142 genotypes were planted at the experimental farm, Division of Crop Improvement, Indian Institute of Sugarcane Research (IISR), Lucknow, during 2016-17 and 2017-18 crop growing seasons in randomized block design (Table 1). Whereas, 47 sugarcane genotypes were planted during 2016-17 and 2017-18 crop growing seasons at the experimental farm of the Padmashri Dr. Vitthalrao Vikhe Patil Sahkari Sakhar Karkhana (PDVVPSSK) Ltd, Pravaranagar, Maharashtrain in alpha design (Table 1).

Symptoms and disease incidence: Based on the visual YLD symptoms, the disease incidence (\%) under field condition was recorded during both the crop growing seasons 2016-17 and 2017-18 on the total 189 sugarcane genotypes planted at IISR, Lucknow, and PDVVPSSK, Ltd., Pravaranagar. Undersub- 
tropical conditions, YLD incidence was recorded in September, November, January, and March during both the 2016-17 and 2017-18 crop growing seasons. Similarly, under tropical condition, the evidence of the occurrence of YLD was recorded during 2016-17 and 2017-18 in 47 sugarcane genotypes.

Sample collection and genomic DNA extraction: In order to detect the phytoplasma infection, a total of 56 YLD affected sugarcane genotype samples including BO 91, BO 111, BO 120, BO 128, BO 129, BO 130, BO 136, BO 137, BO 138, BO 153, CoP 9113, Co 0233, Co 419, Co 453, Co 1336, Co 1148, Co 05011, Co 06425, Co 89003, Co 98014, Co 0118, Co 0238, CoH 92, CoH 99, CoH 119, CoLk 8112, CoLk 94184, CoPant 96219, CoS 245, CoS 510, CoS 687, CoS 797, CoS 91230, CoS 90269, CoS 90265 , CoS 95222, CoS 94270, CoS 93259, CoS 02258, CoS 02264, CoS 8207, CoS 119, CoS 98259, CoSe 00235, CoSe 01235, CoSe 98231, CoSe 01421, Up 05125, CoS 08234, CoPb 08211, CoPb 08217, CoH 08262, CoH 08263, CoLk 09202, CoLk 09204 and CoS 09232, and 39 tropical genotypes exhibiting YLD symptoms were collected and stored in deep freezer $\left(-80^{\circ} \mathrm{C}\right.$ ULT, Haier, India) for further analysis.

Further, these YLD infected leaf samples were subjected for isolation of genomic DNA by CTAB (Cethyl Trimethyl Ammonium Bromide) method. To avoid any cross-contamination in the extracted genomic DNA, all the collected leaf samples were surface cleaned with $70 \%$ ethanol. Genomic DNA extraction was carried out by mixing $500 \mathrm{mg}$ leaf midrib powder in $750 \mu \mathrm{l}$ extraction buffer containing $2 \%$ polyvinylpyrrolidone, incubating at $65^{\circ} \mathrm{C}$ for $60 \mathrm{~min}$, followed by the purification step by addition of equal volume of chloroform-isoamyl alcohol (24:1) and centrifuged for $15 \mathrm{~min}$ at $10000 \mathrm{rpm}$. The supernatant was transferred to a new centrifuge tube. DNA was precipitated by adding equal volume of chilled isopropanol followed by centrifugation at $12000 \mathrm{rpm}$ for $10 \mathrm{~min}$ and discarding the supernatant and by two successive washing of DNA pellets with $70 \%$ ethanol. The purified transparent pellet was eluted in $100 \mu \mathrm{l}$ of TE buffer contained (10 mMTris, 1 mM EDTA, pH 7.6 (Ahrens and Seemuller, 1992) and quality of DNA was checked on $0.8 \%$ agarose gel electrophoresis.

Nested polymerase chain reaction: The nested PCR assay was conducted for the amplification of ribosomal DNA(16S rDNA) using phytoplasma universal primers (P1: 5'AAGAGTTTGATCCTGGCTCAGGATT-3' andP6: 5'CGGTAGGGATCACTTGTTACGACTTA-3') (Deng and Hiruki, 1991) and R16F2n: 5'-GAAACGACTGCTAAGACTGG-3' and R16R2: 5'-TGACGGGCGGTGTGTACAAACCCCG-3') (Gunderson and Lee, 1996; Smart et al. (1996).

First round PCR amplification was performed in a $25 \mu \mathrm{l}$ reaction mixture using Proflex thermal cycler (ProFlex PCR, Thermo Fisher Scientific, USA). The PCR reaction mixture contained $2 \mu$ lof template DNA, $1.5 \mu$ l of $\mathrm{MgCl}_{2}, 0.5 \mu$ of dNTP mixture, $0.5 \mu \mathrm{l}$ of each primer, $0.5 \mathrm{U}$ of TaqDNA polymerase (Dream Taq) and $2.5 \mu$ lof $10 \mathrm{X}$ buffer. The first round PCR amplification protocol was carried out at different temperature conditions; 5 min hot start for initial denaturation at $94^{\circ} \mathrm{C}$, followed by 30 cycles of denaturation at $94^{\circ} \mathrm{C}$ for $30 \mathrm{sec}$, annealing for 1 min at $55^{\circ} \mathrm{C}$ and synthesis at $72^{\circ} \mathrm{C}$ for $1 \mathrm{~min}$, and a cycle of final extension at $72^{\circ} \mathrm{C}$ for $10 \mathrm{~min}$. Further, first round PCR product at a dilution of 1:10 was used as template for the second round PCR with same reaction as described forthe first round PCR. The second round PCR amplification protocol was performed in thermal cycler at similar temperature followed for the first round $\mathrm{PCR}$, except the annealing temperature at $56^{\circ} \mathrm{C}$ for $1 \mathrm{hr}$.

Detection of phytoplasma in different sugarcane plant parts: Samples were collected from YLD affected different plant parts including roots, stem (basal, middle, and upper regions), and leaves (midribs and lamina) from Co 0238 variety. From each plant part, two replications were collected and subjected for isolation of genomic DNA using similar procedure as described above. Tissue culture raised healthy control of same variety Co 0238 was obtained from Division of Crop Improvement, IISR, Lucknow. Further, all the six genomic DNA samples were subjected to nested PCR assay using the similar protocol as described above.

\section{Results and Discussion}

Symptomatology: During 2016-17 and 2017-18 crop growing seasons, the YLD affected sugarcane genotypes exhibited various symptoms like mild yellowing of midribs and smaller leaves, bunching at crown region of plants along with shortened internodes and horizontal spread of yellowing across the leaf lamina, followed by necrosis from leaf tips which continued towards the leaf base. Complete necrosis led to wilting and stunted growth of plants and subsequent complete die-back of plants was observed during severe incidence of YLD under field conditions (Fig.1). Field view of genotypes severely affected due to wide spread occurrence of YLD at IISR, Lucknow and PDVVPSSK, Ltd., Pravaranagar. Similar symptoms have been previously reported on different sugarcane genotypes viz., Co 86032 and CoV 92102 affected by YLD in India (Gaur et al., 2008; Viswanathan and Rao 2011; Rao et al., 2012; Holkar et al., 2016).

During 2013-14 crop growing season, symptoms of YLD were recorded at IISR, Lucknow experimental farm on six genotypes viz., CoS 767, CoJ 64, Co 419, Co 7717, CoLk 94184 , Baragua, Khakai and CoSe 92423. Subsequently, YLD symptomatic samples from two sugarcane varieties i.e., CoLk 94184 and CoSe 92423 were collected and subjected to nested PCR assay followed by sequencing, which revealed the association of new group of phytoplasma (16Srl-B subgroup) with YLD on sugarcane (Kumar et al., 2015). Since, similar type of symptoms of YLD were recorded in more than 100 sugarcane genotypes at the IISR experimental farm (Anonymous, 20142015a, 2015-2016a). In the present study, during 2016-17 and 2017-18 crop growing seasons, symptoms were recorded at maturity stage of crop i.e., in September, November, January, and March and the symptoms observed were development from slightly yellowing of midribs to complete die-back of the crop as 
Table 1: Yellow leaf disease incidence recorded on 189 sugarcane genotypes planted at experimental field of IISR, Lucknow and PDVVPSSK, Ltd., Pravaranagar, during 2016-17 and 2017-18 crop growing seasons

Genotype Planted at Lucknow (142)

(2016 - 17 and $2017-18)$
Genotype planted at Pravaranagar

(47) (2016 - 17 and 2017-18)

CoSnK 05103, Co 14002,Co 14003, Co 14004, Co 14006, CoN 14071, CoN 14072, CoSnK 14101, CoSnK 14102, CoT 14366, CoT 14367, MS 14081, MS 14082, Co 13021, Co 13022, Co 14008, CoVc 14061, CoVc 14062, PI 14131, PI 14132, VSI 14121, VSI 14122, Co 86032, CoC 0671, Co 11005, Co 11007, Co 11012, Co 11019, Co 99004, CoM 11086, CoM 11085, Co 11001, Co 11004, CoM 11081, CoM 11082, CoM 11084, Co 85004, Co 94008, Co 12019 , Co 12024, CoSnK 5103, CoM 12085, Co 12007 , Co 12008 , Co 12009, Co 12012, VSI 12121 the symptoms of YLD are visible at six to eight months after planting of sugarcane (Viswanathan and Rao, 2011; Holkar et al., 2016). Recently, Kumar et al. (2018) have recorded the YLD symptoms on 48 commercial sugarcane varieties across eleven major sugarcane growing states of India viz., Uttarakhand, Uttar Pradesh, Tamil Nadu, Andhra Pradesh, Karnataka, Maharashtra, Punjab, Bihar, Chhattisgarh, Haryana and Assam. This investigation has limited to only 48 genotypes as compared to 189 genotypes from the present study. In addition to this, similar symptoms of yellow leaf disease from different countries from where association of phytoplasma were described including Africa (Arocha et al., 1999; Cronje and Bailey, 1999), Brazil (Silva et al., 2009), Cuba (Aljanabi et al., 2001), Egypt (Elsayed and Boulila, 2014), the USA (Hawaii: Schenck, 1990; Florida: Comstock et al., 1994), Mauritius (Aljanabi, 2001) and Thailand (Soufi et al., 2013).

Disease incidence: Disease incidence was recorded in total 189 sugarcane genotypes planted under tropical and sub-tropical conditions as mentioned in (Table 1). Of the total 142 sub-tropical genotypes, 86 genotypes were found free of YLD whereas, 56 genotypes showed disease incidence ranging from $1.17 \%$ to $65.38 \%$ during $2016-17$ crop growing season. Lowest disease incidence of about $1.17 \%$ was recorded on sugarcane cv. BO 91 whereas the highest disease incidence of about $65.38 \%$ was recorded on CoS 797 during 2016-17 crop growing season (Table 2). Similarly, during 2017-18 crop growing season disease incidence ranged from $7.95 \%$ to $67.44 \%$ among the same 56 genotypes (Table 2). During both crop growing seasons, 86 genotypes were found free of prominent YLD symptoms and were therefore treated as apparently healthy as compared to rest of 56 genotypes which showed prominent YLD symptoms under field conditions. Moreover, the disease incidence was also recorded in 47 tropical sugarcane genotypes during 2016-17and 2017-18 crop growing seasons and of which 39 genotypes were found affected due to YLD, and incidence ranged from $3.89 \%$ to $55.58 \%$ and $2.38 \%$ to $80.39 \%$, respectively. No prominent visual symptoms were recorded on eight genotypes, including CoN 14072, MS 14082, Co11012, Co 12012, CoM11085, CoM 11082, CoSnK 5103, and CoM 12085 (Table 3).

In India, YLD incidence was recorded and found varied with genotype to genotype and location to location during 2012-13 to 2016-17 including, $10-80 \%$ at Anakapalle, $2 \%$ at Akola, $2-5 \%$ at Buralikson, $5-40 \%$ at Cuddalore, $2-11 \%$ in Karnataka, 2-25\% at Kolhapur, 5-11\% at Padegaon, Traces-15\% at Powarkheda, $1-5 \%$ at Pune, 3-20\% in Bihar (Pusa), 2-11\% at Sankeshwar, 10-15\% at Seorahi, $1-30 \%$ at Shahjahanpur, Traces-5\% at Uchani, traces-4\% at Hoshangabad, Betul and Bankhedi, $10-60 \%$ at Vijayanagaram, Vishakhapattanam, Karimnagar, Nizamabad, East Godavari and Chittor, 2-11\% at Haveri, Bagalkot, Dharwad and Belgaon, 15-30\% at Pondicherry, Villupuram, Seithiathope, Mundiyapakkam, and in traces at Thiruvalla, Shahabad, Rohtak, Sitarganj, Kiccha, Gadarpur, Kashipur, Bardoli, Iramallikk, Thiruvandoor and Vallamkulam (Anonymous, 2011-2012, 20122013, 2013-2014, 2014-2015b, 2015-2016b).

In India, incidence of YLD has been recorded up to $100 \%$ in different susceptible varieties (Viswanathan et al., 1999; Rao et al., 2001). Since its first record, incidence of YLD on sugarcane was observed in the major sugarcane growing states viz., Uttar Pradesh, Maharashtra, Tamil Nadu and Haryana (Viswanathan and Rao, 2011; Holkar et al., 2016). Similarly, YLD incidence was also observed up to $60 \%$ in different susceptible varieties in Andhra Pradesh and Telangana states (Rajkumar et al., 2014). Holkar et al. (2016) recorded up to $29.95 \%$ of YLD incidence in more than 40 sugarcane genotypes from sub-tropical India.In addition to this, YLD incidence was reported from the USAin five Saccharum species viz., S. spontaneum (7.0\%), S. officinarum 
Table 2: Yellow leaf disease incidence and nested PCR assay of 142 sub-tropical sugarcane genotypes planted at IISR, Lucknow, during 2016-17 and 2017-18 crop growing seasons

\begin{tabular}{|c|c|c|c|c|c|c|c|c|c|}
\hline \multirow[t]{2}{*}{ Genotype } & \multicolumn{2}{|c|}{$\begin{array}{l}\text { Disease incidence } \\
(\%)\end{array}$} & \multicolumn{2}{|c|}{$\begin{array}{l}\text { Nested PCR } \\
\text { assay }(2016-17)\end{array}$} & \multirow[t]{2}{*}{ Genotype } & \multicolumn{2}{|c|}{$\begin{array}{l}\text { Disease incidence } \\
(\%)\end{array}$} & \multicolumn{2}{|c|}{$\begin{array}{l}\text { Nested PCR assay } \\
(2017-18)\end{array}$} \\
\hline & 2016-17 & 2017-18 & First round & Second round & & 2016-17 & 2017-18 & First round & Second round \\
\hline BO 91 & 1.17 & 7.95 & -ve & $+v e$ & $\operatorname{CoS} 687$ & 20.08 & 30.29 & -ve & +ve \\
\hline BO 99 & 0 & 0 & -ve & $-v e$ & $\operatorname{CoS} 770$ & 0 & 0 & $-v e$ & $-v e$ \\
\hline BO 119 & 0 & 0 & -ve & -ve & Cos 767 & 0 & 0 & -ve & -ve \\
\hline BO 111 & 1.72 & 12.74 & -ve & +ve & CoS 797 & 65.38 & 63.92 & +ve & +ve \\
\hline BO 120 & 7.74 & 19.83 & -ve & +ve & CoS 91269 & 0 & 0 & $-v e$ & $-v e$ \\
\hline BO 128 & 9.67 & 25.17 & -ve & $+v e$ & Cos 91230 & 38.71 & 67.44 & +ve & +ve \\
\hline BO 129 & 9.06 & 33.03 & -ve & +ve & CoS 90269 & 26.04 & 30.84 & $-v e$ & +ve \\
\hline BO 130 & 8.7 & 20.2 & -ve & +ve & CoS 90265 & 30.80 & 37.26 & +ve & +ve \\
\hline BO 136 & 9.66 & 23.67 & -ve & +ve & CoS 88230 & 0 & 0 & -ve & $-v e$ \\
\hline BO 137 & 8.27 & 26.38 & -ve & +ve & $\operatorname{CoS} 8436$ & 0 & 0 & -ve & $-v e$ \\
\hline BO 138 & 7.39 & 25.04 & -ve & +ve & CoS 95270 & 0 & 0 & $-v e$ & $-v e$ \\
\hline BO 139 & 0 & 0 & -ve & $-v e$ & CoS 95255 & 0 & 0 & -ve & $-v e$ \\
\hline BO 141 & 0 & 0 & -ve & -ve & CoS 95222 & 2.18 & 10.87 & -ve & +ve \\
\hline BO 145 & 0 & 0 & -ve & -ve & CoS 94270 & 10.52 & 18.01 & $-v e$ & +ve \\
\hline BO 147 & 0 & 0 & -ve & -ve & CoS 94257 & 0 & 0 & -ve & -ve \\
\hline BO 153 & 2.91 & 16.46 & -ve & +ve & CoS 93259 & 18.07 & 39.45 & +ve & +ve \\
\hline CoP 9113 & 2.72 & 11.84 & -ve & +ve & Cos 01256 & 0 & 0 & -ve & -ve \\
\hline CoP 9206 & 0 & 0 & -ve & -ve & CoS 02258 & 27.94 & 48.77 & +ve & +ve \\
\hline CoP 9301 & 0 & 0 & -ve & -ve & CoS 02264 & 27.42 & 53.39 & $+v e$ & $+v e$ \\
\hline CoP 9302 & 0 & 0 & -ve & -ve & CoS 03279 & 0 & 0 & $-v e$ & $-v e$ \\
\hline CoP 9702 & 0 & 0 & -ve & -ve & Cos 07250 & 0 & 0 & -ve & $-v e$ \\
\hline Co 0124 & 0 & 0 & -ve & -ve & CoS 7918 & 0 & 0 & -ve & -ve \\
\hline Co 0232 & 0 & 0 & -ve & -ve & CoS 8118 & 0 & 0 & $-v e$ & $-v e$ \\
\hline Co 0233 & 22.12 & 33.53 & $+v e$ & +ve & CoS 8207 & 13.88 & 21.65 & $-v e$ & $+v e$ \\
\hline Co 0237 & 0 & 0 & -ve & -ve & CoS 8315 & 0 & 0 & -ve & $-v e$ \\
\hline Co 419 & 23.15 & 43.55 & -ve & +ve & CoS 119 & 15.03 & 22.43 & $-v e$ & $+v e$ \\
\hline Co 453 & 32.95 & 49.48 & -ve & $+v e$ & CoS 8432 & 0 & 0 & $-v e$ & $-v e$ \\
\hline Co 1336 & 20.24 & 31.91 & -ve & +ve & CoS 96258 & 0 & 0 & -ve & $-v e$ \\
\hline Co 1148 & 25.16 & 43.05 & +ve & +ve & CoS 96268 & 0 & 0 & -ve & -ve \\
\hline Co 05011 & 24.68 & 38.04 & -ve & $-v e$ & CoS 96269 & 0 & 0 & $-v e$ & $-v e$ \\
\hline Co 06425 & 28.12 & 37.86 & -ve & +ve & CoS 96275 & 0 & 0 & $-v e$ & $-v e$ \\
\hline Co 6811 & 0 & 0 & -ve & -ve & CoS 97258 & 0 & 0 & -ve & -ve \\
\hline Co 87263 & 0 & 0 & -ve & -ve & CoS 97261 & 0 & 0 & $-v e$ & $-v e$ \\
\hline Co 872683 & 0 & 0 & -ve & -ve & CoS 97264 & 0 & 0 & -ve & -ve \\
\hline Co 89003 & 20.38 & 31.21 & -ve & +ve & CoS 99259 & 0 & 0 & -ve & -ve \\
\hline Co 89029 & 0 & 0 & -ve & $-v e$ & CoS 98259 & 18.09 & 26.88 & -ve & +ve \\
\hline Co 98014 & 34.13 & 48.51 & -ve & $+v e$ & CoSe 00235 & 9.75 & 26.11 & $-v e$ & $+v e$ \\
\hline Co 0118 & 17.85 & 34.39 & -ve & $+v e$ & CoSe 01235 & 27.05 & 41.04 & $-v e$ & $+v e$ \\
\hline Co 0238 & 22.26 & 29.81 & +ve & +ve & CoSe 98231 & 23.73 & 38.77 & -ve & +ve \\
\hline Co 0239 & 0 & 0 & -ve & $-v e$ & CoSe 96436 & 0 & 0 & -ve & $-v e$ \\
\hline CoB 94164 & 0 & 0 & -ve & -ve & CoSe 95436 & 0 & 0 & $-v e$ & $-v e$ \\
\hline $\mathrm{CoH} 56$ & 0 & 0 & -ve & $-v e$ & CoSe 95422 & 0 & 0 & -ve & -ve \\
\hline $\mathrm{CoH} 92$ & 33.85 & 50.44 & +ve & $+v e$ & CoSe 92423 & 0 & 0 & -ve & -ve \\
\hline $\mathrm{CoH} 99$ & 39.28 & 40.39 & $+v e$ & $+v e$ & CoSe 08457 & 0 & 0 & $-v e$ & $-v e$ \\
\hline $\mathrm{CoH} 111$ & 0 & 0 & $-v e$ & $-v e$ & CoSe 05451 & 0 & 0 & $-v e$ & $-v e$ \\
\hline $\mathrm{CoH} 119$ & 28.46 & 49.96 & -ve & $+v e$ & CoSe 03234 & 0 & 0 & -ve & -ve \\
\hline CoJ 64 & 0 & 0 & -ve & $-v e$ & CoSe 01434 & 0 & 0 & $-v e$ & $-v e$ \\
\hline CoJ 83 & 0 & 0 & -ve & -ve & CoSe 01424 & 0 & 0 & -ve & -ve \\
\hline
\end{tabular}


Table 2: Yellow leaf disease incidence and nested PCR assay of 142 sub-tropical sugarcane genotypes planted at IISR, Lucknow, during $2016-17$ and 2017-18 crop growing seasons

\begin{tabular}{|c|c|c|c|c|c|c|c|c|c|}
\hline \multirow[t]{2}{*}{ Genotype } & \multicolumn{2}{|c|}{$\begin{array}{l}\text { Disease incidence } \\
(\%)\end{array}$} & \multicolumn{2}{|c|}{$\begin{array}{l}\text { Nested PCR } \\
\text { assay }(2016-17)\end{array}$} & \multirow[t]{2}{*}{ Genotype } & \multicolumn{2}{|c|}{$\begin{array}{l}\text { Disease incidence } \\
(\%)\end{array}$} & \multicolumn{2}{|c|}{$\begin{array}{l}\text { Nested PCR assay } \\
(2017-18)\end{array}$} \\
\hline & 2016-17 & 2017-18 & First round & Second round & & 2016 - 17 & 2017 - 18 & First round & Second round \\
\hline CoJ 85 & 0 & 0 & -ve & -ve & CoSe 01421 & 44.92 & 54.45 & +ve & +ve \\
\hline CoJ 88 & 0 & 0 & -ve & -ve & UP 9530 & 0 & 0 & -ve & -ve \\
\hline CoJ 89 & 0 & 0 & -ve & -ve & UP 05125 & 2.29 & 8.34 & -ve & +ve \\
\hline CoLk 790 & 0 & 0 & -ve & -ve & UP 0097 & 0 & 0 & -ve & -ve \\
\hline CoLk 8001 & 0 & 0 & -ve & -ve & UP 05 & 0 & 0 & -ve & -ve \\
\hline CoLk 8112 & 12.23 & 24.9 & -ve & +ve & UP 39 & 0 & 0 & -ve & -ve \\
\hline CoLk 94184 & 16.25 & 32.3 & +ve & +ve & CoS 08279 & 0 & 0 & -ve & $-v e$ \\
\hline CoLk 9709 & 0 & 0 & -ve & -ve & CoS 8233 & 0 & 0 & -ve & -ve \\
\hline CoLk 07201 & 0 & 0 & -ve & -ve & CoS 08234 & 19.21 & 31.23 & -ve & +ve \\
\hline CoPant 03220 & 0 & 0 & -ve & -ve & CoS 08235 & 0 & 0 & -ve & -ve \\
\hline CoPant 05224 & 0 & 0 & -ve & -ve & $\mathrm{CoPb} 08211$ & 21.8 & 43.39 & +ve & +ve \\
\hline CoPant 24211 & 0 & 0 & -ve & -ve & $\mathrm{CoPb} 08212$ & 0 & 0 & -ve & $-v e$ \\
\hline CoPant 84212 & 0 & 0 & -ve & -ve & $\mathrm{CoPb} 08217$ & 12.09 & 37.75 & -ve & +ve \\
\hline CoPant 90223 & 0 & 0 & -ve & -ve & $\mathrm{CoH} 08262$ & 23.48 & 45.04 & +ve & +ve \\
\hline CoPant 96219 & 19.41 & 32.87 & +ve & +ve & $\mathrm{CoH} 08263$ & 30.84 & 45.10 & +ve & +ve \\
\hline CoPant 97222 & 0 & 0 & -ve & -ve & $\mathrm{CoH} 08264$ & 0 & 0 & -ve & $-v e$ \\
\hline CoPant 99214 & 0 & 0 & -ve & -ve & CoLk 09202 & 1.64 & 9.65 & -ve & +ve \\
\hline CoPk 05191 & 0 & 0 & -ve & -ve & CoLk 09204 & 3.43 & 12.65 & $-v e$ & $+v e$ \\
\hline CoS 245 & 30.24 & 45.13 & +ve & +ve & $\mathrm{CoPb} 09181$ & 0 & 0 & -ve & $-v e$ \\
\hline $\operatorname{CoS} 443$ & 0 & 0 & -ve & -ve & Cos 09232 & 22.16 & 46.47 & -ve & +ve \\
\hline $\operatorname{CoS} 510$ & 56.96 & 63.13 & +ve & +ve & Co 09022 & 0 & 0 & $-v e$ & $-v e$ \\
\hline CoS 514 & 0 & 0 & -ve & -ve & $\mathrm{CoH} 09264$ & 0 & 0 & -ve & -ve \\
\hline CoS 541 & 0 & 0 & -ve & -ve & $\mathrm{CoH} 09264$ & 0 & 0 & -ve & -ve \\
\hline
\end{tabular}

Table 3: Yellow leaf disease incidence recorded in 47 sugarcane genotypes planted at PDVVSSK, Ltd., Pravaranagar during and 2017-18 crop growing seasons

\begin{tabular}{llllll}
\hline Genotype & Disease incidence (\%) & Genotype & Disease incidence (\%) & Genotype & Disease incidence (\%) \\
\hline CoSnK 05103 & 12.00 & CoVc 14061 & 2.50 & Co 11004 & 15.56 \\
Co 14002 & 11.11 & CoVc 14062 & 7.32 & CoM 11081 & 7.5 \\
Co 14003 & 4.55 & PI 14131 & 28.13 & CoM 11082 & 0.00 \\
Co 14004 & 8.00 & PI 14132 & 13.89 & CoM 11084 & 6.9 \\
Co 14006 & 6.45 & VSI 14121 & 5.13 & Co 85004 & 32.08 \\
CoN 14071 & 7.50 & VSI 14122 & 62.96 & Co 94008 & 36.67 \\
CoN 14072 & 0.00 & Co 86032 & 30.00 & Co 12019 & 80.39 \\
CoSnK 14101 & 20.69 & CoC 0671 & 11.54 & Co 12024 & 45.45 \\
CoSnK 14102 & 4.76 & Co 11005 & 32.56 & CoSnK 5103 & 0.00 \\
CoT 14366 & 8.57 & Co 11007 & 28.57 & CoM 12085 & 0.00 \\
CoT 14367 & 2.63 & Co 11012 & 0.00 & Co 12007 & 36.84 \\
MS 14081 & 11.43 & Co 11019 & 11.76 & Co 12008 & 13.89 \\
MS 14082 & 0.00 & Co 99004 & 25.71 & Co 12009 & 5.13 \\
Co 13021 & 25.00 & CoM 11086 & 2.38 & VSI 12121 & 39.47 \\
Co 13022 & 37.93 & CoM 11085 & 0.00 & Co 12012 & 0.00 \\
Co 14008 & 28.13 & Co 11001 & 28.95 & & \\
\hline
\end{tabular}

(75.8\%), S. robustum (62.5\%), S. sinense (46.2\%), and S. barberi (13.6\%) (Comstock et al., 2001) but they have detected the presence of SCYLV instead of phytoplasma as YLD is caused by single or mixed infection of SCYLV and phytoplasma. However, scanty information is available on incidence of YLD in large number of genotypes from sub-tropical conditions in India. The disease incidence was recorded during 2016-2017 and 2017-2018 seasons, in which the variety BO 91 showed 


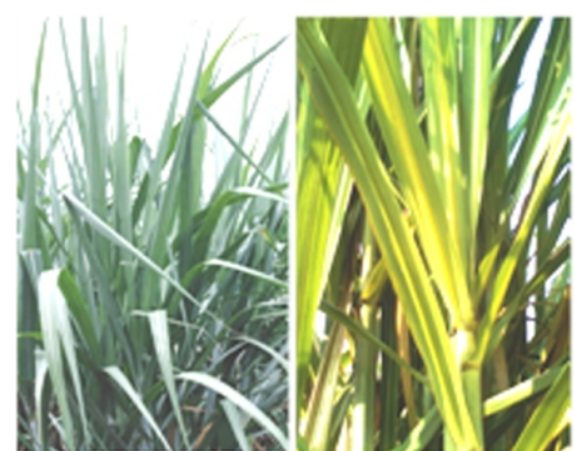

(A)
(B)

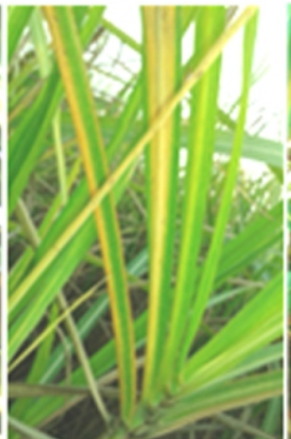

(C)

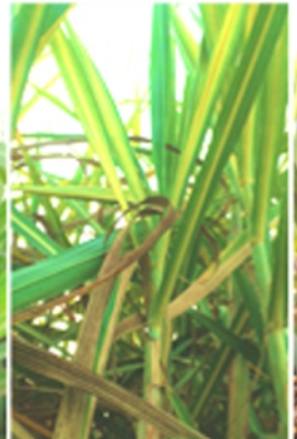

(D)

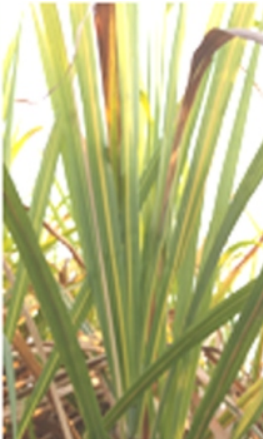

$(\mathrm{E})$

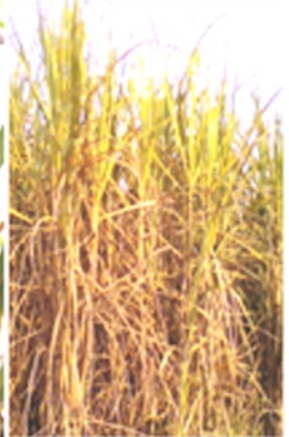

(F)

Fig. 1: Symptoms of healthy and yellow leaf diseased sugarcane plants. (A) plant with green leaves and midribs; (B) mild yellowing of the midribs and smaller leaves; (C) bunching at the crown region of the plant along with shortened internodes; (D) yellowing was spread laterally across the leaf lamina; (E) necrosis starts from leaf tips which continued towards the leaf base and $(F)$ complete necrosis led to the wilting and stunted growth and subsequently complete die-back of plants.

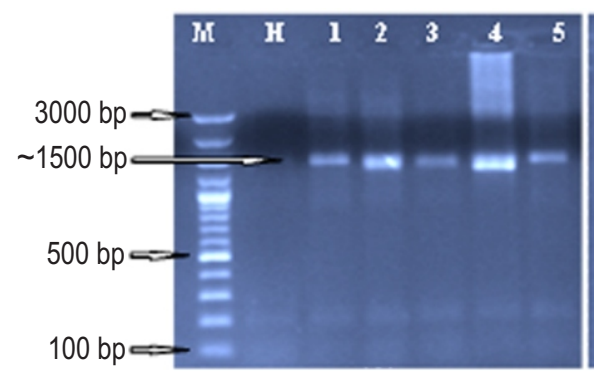

(A)

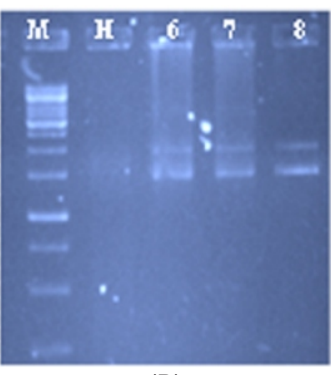

(B)

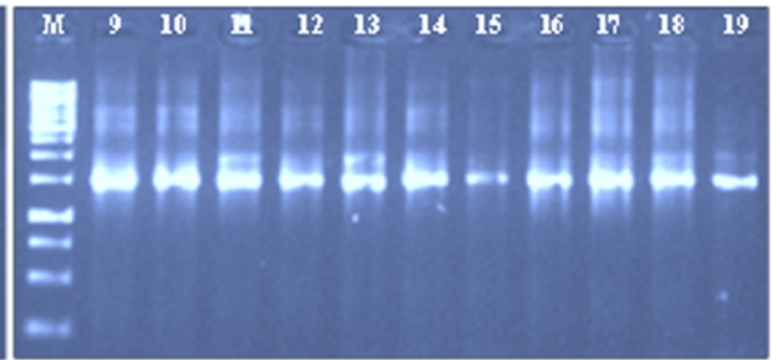

(C)

Fig. 2: 1.5\% agarose gel electrophoresis of the first round nested PCR amplification of phytoplasma using P1/P6 universal primers showed amplification of $\sim 1.5 \mathrm{~Kb}$ size amplicons in all the 19 samples. Lanes; 1: Co 1148, 2: Co 0238, 3: CoPant 96219, 4: CoS 02258, 5: CoS 02264, 6: Co 0233, 7: CoLk 94184, 8: CoH 92, 9: CoH 99, 10: CoS 245, 11: CoS 510, 12: CoS 797, 13: CoS 91230, 14: CoS 90265, 15: CoS 93259, 16: CoSe 01421, 17: CoPb 08211, 18: $\mathrm{CoH} 08262$ and 19: $\mathrm{CoH} 08263 ; \mathrm{M}=100$ bp plus DNAladder in Aand $1 \mathrm{~Kb}$ DNAladder in $\mathrm{B}$ and $\mathrm{C} ; \mathrm{H}=$ healthy control.

minimum disease incidence of $1.17 \%$ and $7.95 \%$ whereas, CoS 797 showed maximum disease incidence of $65.38 \%$ and $67.44 \%$ in 2016-17 and 2017-18 seasons, respectively. It was observed that the disease incidence increased slightly in all genotypes cultivated during 2017-18 crop growing season as compared to 2016-17. This could be due to the transmission of phytoplasma via infected seed cane used for planting and or by insect vector. Likewise, sub-tropical conditions, incidence was also recorded in 39 tropical genotypes exhibiting the similar symptoms.

Nested PCR assay: Total 56 genomic DNA samples isolated from YLD affected sub-tropical sugarcane plants were subjected to first round of nested PCR assay which resulted in the amplification of $\sim 1.5 \mathrm{~Kb}$ size amplicons in the 19 samples indicated in (Fig. 2; Table 2). Whereas, second round PCR of these 56 samples using the first round PCR product as a template resulted in the amplification of $\sim 1.2 \mathrm{~Kb}$ size amplicons in 55 samples except one sample as indicated (Fig. 3; Table 2). The YLD affected genotype i.e., Co 05011 showed no amplification in either of the rounds of nested PCR assay. Thus, from the present study it was evident that among the total YLD samples subjected to nested PCR, $98 \%$ samples $(n=55)$ revealed the association of phytoplasma using nested PCR assay. Similarly, of the total 47 tropical genotypes, 39 genotypes showed the amplification of $\sim 1.2 \mathrm{~Kb}$ size amplicons in second round nested PCR assay (Data not shown). Using similar procedure which used in the present study was earlier followed by different workers and obtained similar amplicon sizes of about $1.2 \mathrm{~Kb}$ in nested PCR.

The association of SCYP belonging to Aster yellows phytoplasma (16Srl-A subgroup) with YLD was first reported by Arocha et al. (1999). Subsequently, Cronje and Bailey (1999) detected different strains of phytoplasma associated with YLD belonging to Western-X phytoplasma of $16 \mathrm{Srlll}$ group. From Brazil, Silva et al. (2009) identified the association of SCYP belonging to Aster yellows phytoplasma (16Srl-B subgroup) with yellow leaf disease of sugarcane. Later, Soufi and Komor (2014) reported that the yellow leaf symptom of sugarcane was caused by SCYP of $16 \mathrm{Srl}$ group (Aster yellows phytoplasma) in Thailand. Whereas in Egypt, similar results have been submitted by 


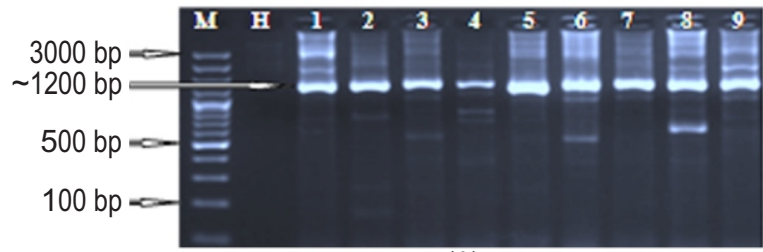

(A)

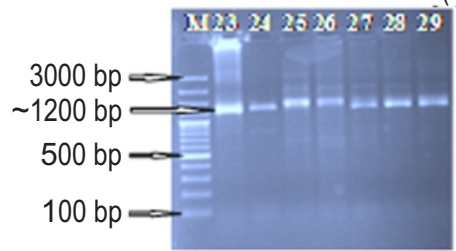

(D)

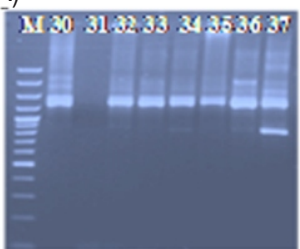

$(\mathrm{E})$

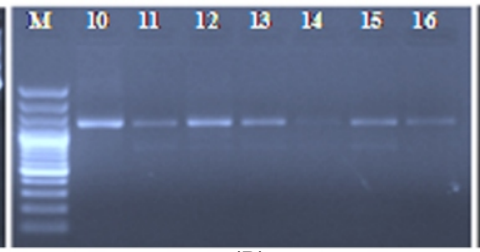

(B)

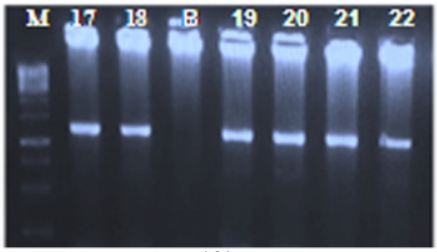

(C)

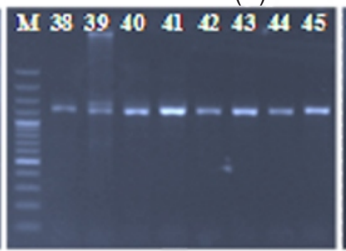

$(\mathrm{F})$

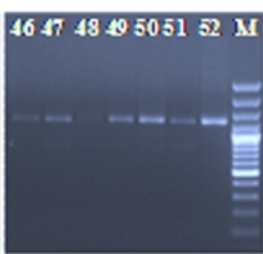

(G)

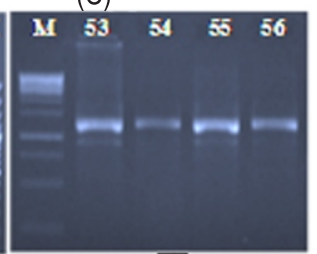

$(\mathrm{H})$

Fig. 3: 1.5\% agarose gel electrophoresis of the second round nested PCR amplification of phytoplasma using R16F2n/R16R2 universal primers showed amplification of $\sim 1.2 \mathrm{~Kb}$ size amplicons in all the 55 samples. Lanes; 1: BO 91, 2: BO 111, 3: BO 120, 4: BO 128, 5: BO 129, 6: BO 130, 7: BO 136, 8: BO 137, 9: BO 138, 10: BO 153, 11: CoP 9113, 12: Co 419, 13: Co 453, 14: Co 1336, 15: Co 06425, 16: Co 89003, 17: Co 98014, 18: Co 0118, 19: CoH 119, 20: Colk 8112, 21: CoPant 96219, 22: Co 0233, 23: Co 1148, 24: Co 0238, 25: CoH 92, 26: CoH 99, 27: CoLk 94184, 28: CoS 510, 29: CoS 245, 30: CoS 687, 31: *Co 05011, 32: CoS 797, 33: CoS 91230, 34: CoS 90269, 35: CoS 90265, 36: CoS 95222, 37: CoS 94270, 38: CoS 93259, 39: CoS 02258, 40: CoS 02264, 41: CoS 8207, 42: CoS 119, 43: COS 98259, 44: CoSe 00235, 45: CoSe 01235, 46: CoSe 98231, 47: CoSe 01421, 48: Up 05125, 49: CoS 08234, 50: CoPb 08211, 51: CoPb 08217, 52: CoH 08262, 53: CoH 08263, 54: CoLk 09202, 55: CoLk 09204 and 56: CoS 09232; M= 100 bp plus DNA ladder in $\mathrm{A}, \mathrm{B}, \mathrm{D}, \mathrm{E}, \mathrm{F}$ and $\mathrm{G}$ and $1 \mathrm{~Kb}$ DNA ladder in $\mathrm{C}$ and $\mathrm{H} ; \mathrm{H}=$ healthy sample, $\mathrm{B}=\mathrm{Blank}$ and ${ }^{*}=$ Not amplified.

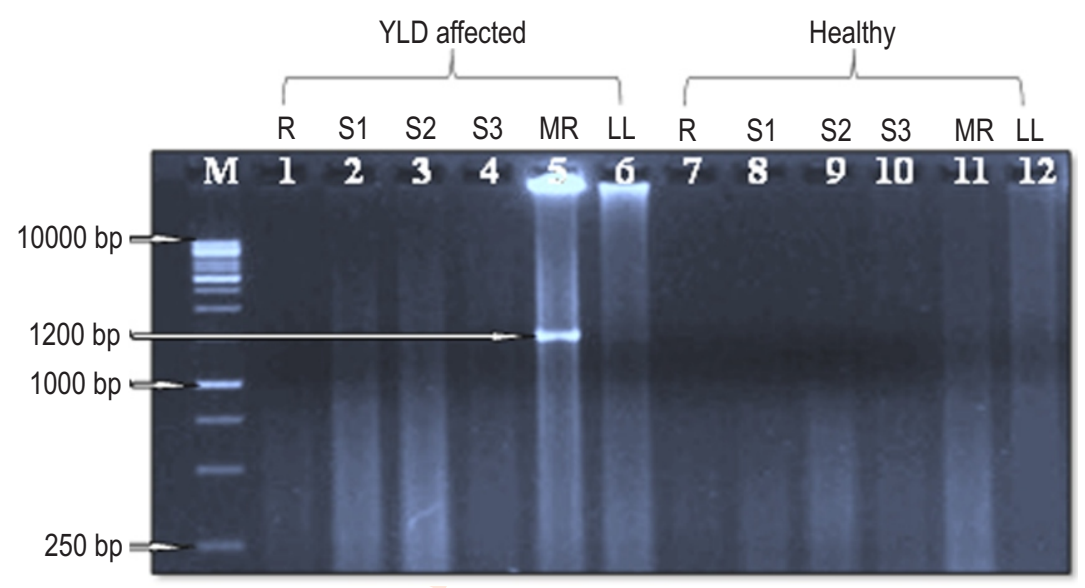

Fig. 4: 1.5\% agarose gel electrophoresis of the nested PCR amplification of phytoplasma from the YLD infected sugarcane samples originating from different plant parts of Co 0238. Lanes; 1: roots (R), 2: basal stem regions (S1), 3: middle stem regions (S2), 4: upper stem regions (S3), 5: leaf midribs (MR) and 6: leaf lamina (LL) of YLD affected samples and Lanes; 7: roots (R), 8: basal stem regions (S1), 9: middle stem regions (S2), 10: upper stem regions (S3), 11: leaf midribs (MR) and 12: leaf lamina (LL) of healthy control; $M=1 \mathrm{~Kb}$ DNAladder.

Elsayed and Boulila (2014) on the association of Aster yellows phytoplasma. To detect the presence of phytoplasma in different sugarcane plant parts, samples were collected from the leaf midrib and leaf lamina of YLD affected Co 0238 variety which showed amplification of $\sim 1.2 \mathrm{~Kb}$ size amplicons. Whereas, samples from roots, basal, middle, and upper stem regions and healthy control from same variety showed no amplification. This confirmed that the phytoplasma showed its presence in the midrib and leaf lamina region of affected plants (Fig. 4; Lanes: 5 and 6). In India, Gaur et al. (2008) for the first time reported the association of $16 \mathrm{SrXII}$ group of phytoplasma with YLD in sugarcane. Later, the association of ' $\mathrm{Ca}$. P. asteris' of $16 \mathrm{Srl}-\mathrm{B}$ subgroup was detected in two YLD infected sugarcane genotypes viz., CoLk 94184 and CoSe 92423in India, during 2014-15 (Accession No.: KJ599656 and KJ599657) (Kumar et al., 2015). Recently in India, Kumar et al. (2018) have further 
confirmed the association of $16 \mathrm{Srl}-\mathrm{B}$ subgroup of phytoplasma in four YLD affected sugarcane varieties. Therefore, in the present study 189 genotypes were selected for recording YLD incidence following Kumar et al. (2015) as baseline information. Further, sequence information of more phytoplasma isolates is required to have clear understanding about the existence of genetic diversity and association of single or mixed infections of SCYP, SCWLP and SCGSP in the YLD affected sugarcane genotypes in India.

As SCYLV is one of the causal pathogens of YLD, recently, Boukari et al. (2020) investigated the transmission efficiency of SCYLV by aphid (Melanaphis sacchari) on YLD susceptible sugarcane cultivar CP96-1252 and the inoculated plants were found negative for the presence of SCYLV by tissue blot immunoassay (TBIA) and reverse transcription polymerase chain reaction (RT-PCR). The results revealed that the $M$. sacchari is one of the prominent vector of SCYLV in different parts of the world but it is not a vector of SCYLV in Florida. Similarly, the phytoplasma-vector interaction studies and possibility of new vectors need to identify for devising suitable management strategies to stop the secondary spread of phytoplasma in India.

Moreover, all these 142 sub-tropical genotypes were also subjected to DAS-ELISA for detecting the presence of SCYLV but none of the samples reacted positively against specific antiserum (AC diagnostic, USA). Keeping in mind the heavy losses incurred in cane yield and yield contributing parameters due to YLD in sugarcane, it is important to assess its incidence and wide spread prevalence in different sugarcane genotypes. In the present study, of the 142 sub-tropical genotypes 38\% (55 genotypes) of YLD affected genotypes were found positive for phytoplasma through nested PCR, while remaining 62\% genotypes (87 genotypes) were found without any prominent YLD symptoms and needs further confirmation on possibility of latent infection in these genotypes. Similarly, of the 47 tropical genotypes $83 \%$ (39 genotypes) were found affected due to YLD, while eight genotypes were found healthy and needs further confirmation of latent infections of SCYLV and phytoplasma. Thus, findings from the present study showed that the association of phytoplasma with YLD of sugarcane in 55 and 39 genotypes from sub-tropical and tropical conditions of India. Apparently healthy genotypes need to be confirmed and further used in developing YLD resistant progenies and or genotypes in India.

\section{Acknowledgments}

The authors are highly grateful to Dr. A. D. Pathak, Director, ICAR-IISR, Lucknow and Dr. Sanjeev Kumar (Biotechnology), IISR, Lucknow, for providing laboratory facilities to carry out the present work.

\section{References}

Ahrens, U. and E. Seemuller: Detection of DNA of plant pathogenic mycoplasma-like organisms by a polymerase chain reaction that amplifies a sequence of the 16S rRNA gene. Phytopathology, 82, 828-832(1992).
Aljanabi, S.M., Y. Parmessur, Y. Moutia, S. Saumtally and A. Dookun: Further evidence of the association of a phytoplasma and a virus with yellow leaf syndrome in sugarcane. Plant Pathol., 50, 628-36 (2001).

Anonymous: Annual Report, All India Coordinated Research Project on Sugarcane, IISR, Lucknow (2011-12).

Anonymous: Annual Report, All India Coordinated Research Project on Sugarcane, IISR, Lucknow (2012-13).

Anonymous: Annual Report, All India Coordinated Research Project on Sugarcane, IISR, Lucknow (2013-2014).

Anonymous: Annual Report, All India Coordinated Research Project on Sugarcane, IISR, Lucknow (2014-2015b).

Anonymous: Annual Report, All India Coordinated Research Project on Sugarcane, IISR, Lucknow, pp. 1-80 (2015-2016b).

Anonymous: Annual Report, Indian Institute of Sugarcane Research, Lucknow, India, pp. 1-124 (2014-2015a).

Anonymous: Annual Report, Indian Institute of Sugarcane Research, Lucknow, India, pp. 1-145 (2015-2016a).

Arocha, Y., M. Lopez, M. Fernandez, B. Pinol, D. Horta, E.L. Peralta, R. Almeida, O. Carvajal, S. Picornell, M.R. Wilson and P. Jones: Transmission of a sugarcane yellow leaf phytoplasma by the delphacid plant hopper Saccharosydne saccharivora, a new vector of sugarcane yellow leaf syndrome. Plant Pathol., 54, 634$642(2005)$

Arocha, Y., P. Jones, I. Sumac and E.L. Peralta: Detection of phytoplasma associated with yellow leaf syndrome in Cuba. Revista de Proteccion, Vegetal., 15, 81-87 (2000).

Arocha, Y.L., L. Gonzales, E.L. Peralta and P. Jones: First report of virus and phytoplasma pathogens associated with yellow leaf syndrome of sugarcane in Cuba. Plant Dis., 83, 1177-1177 (1999).

Bailey, R., G. Bechet and P. Cronje: Notes on the occurrence of yellow leaf syndrome of sugarcane in southern Africa. Proceedings of the South African Sugar Technologists Association, 70, 3-6 (1996).

Boukari, W., C. Wei, L. Tang, M. Hincapie, M. Naranjo, G. Nuessly, J. Beuzelin, S. Sood and P. Rott: Lack of transmission of Sugarcane yellow leaf virus in Florida from Columbus grass and sugarcane to sugarcane with aphids or mites. PLOS ONE, 15, e0230066 (2020).

Comstock, J.C., J.D. Miller and R.J. Schnell: Incidence of sugarcane yellow leaf virus in clones maintained in the world collection of sugarcane and related grasses at the United States national repository in Miami, Florida. Sugar Tech., 3, 128-133 (2001).

Comstock, J.C., J.E. Irvine and J.D. Miller: Yellow leaf syndrome appears on the United States mainland. Sugar Journal, 56, 33-35 (1994).

Cronje, C.P.R. and R.A. Bailey: Association of phytoplasma with yellow leaf syndrome of sugarcane. In Proceedings of the XXIII Congress of the International Society of Sugar Cane Technologists. New Delhi, India: ISSCT Congress., pp. 373-80 (1999).

Cronje, C.P.R., A.M. Tymon, P. Jones and R.A. Bailey: Association of a phytoplasma with a yellow leaf syndrome of sugarcane in Africa. Annals App. Biol., 133, 177-186 (1998).

Deng, S. and C. Hiruki: Amplification of $16 \mathrm{~S}$ rRNA genes from culturable and non-culturable mollicutes. J. Microbiol. Meth., 14, 53-61 (1991).

Elsayed, A.I. and B. Moncef: Molecular Identification and Phylogenetic Analysis of Sugarcane Yellow Leaf Phytoplasma (SCYLP) in Egypt. J. Phytopathol., 162, 89-97 (2014).

Gatineau, F., J. Larrue, D. Clair, F. Lorton, M. Richard-Molarc and E. Boudon-Padieu: A new natural planthopper vector of Stolbur phytoplasma in the genus Pentastiridis (Hemiptera: Cixiidae). Eur. J. Plant Pathol., 107, 263-271 (2001).

Gaur, R.K., R. Raizada and G.P. Rao: Sugarcane yellow leaf phytoplasma associated for the first time with sugarcane yellow leaf syndrome in India. Plant Pathol., 57, 772 (2008). 
Gunderson, D.E. and I.M. Lee: Ultrasensitive detection of phytoplasma by nested-PCR assays using two universal primer pairs. Phytopathol. Mediterr., 35, 144-151 (1996).

Holkar, S.K., H. Gupta, A. Kumar, A. Baitha, S. Kumar and J. Singh: Diagnosis of Yellow Leaf Disease of sugarcane from Sub-tropical India. Indian Phytopathological Society-MEZ and ICAR-IIPR, Kanpur, India, 29 $9^{\text {th }}-30^{\text {th }}$ December, S5-PP-27, page 177 (2016).

Kumar, S., G.P. Rao, V.S. Jadon and V.K. Baranwal: Genetic diversity of phytoplasmas associated with sugarcane grassyshoot and leaf yellows diseases in India. Phytopathogenic Mollicutes, 8, 74-88 (2018).

Kumar. S., A.K. Tiwari, S.K. Holkar, S.K. Duttamajumder and G.P. Rao: Characterization of a $16 \mathrm{Srl}-\mathrm{B}$ subgroup phytoplasma associated with sugarcane leaf yellows disease in India. Sugar Tech, 17, 156161 (2015).

Maixner, M. and W. Reinert: Oncopsisalni (Schranck) (Auchenorrhyncha: Cicadellidae) as a vector of the alder yellows phytoplasma of Alnusglutinosa (L.) Gaertn. Eur. J. Plant Pathol., 105, 87-94 (1999).

Rajkumar, N., M. Suresh, K. Prasada Rao and R. Ankaiah: Current status of sugarcane diseases in Andhra Pradesh. Proceedings of AICRP on Sugarcane group meet., $25^{\text {th }}-26^{\text {th }}$ October, pp. 97-98 (2014).

Rao, G.P., R.K. Gaur, M. Singh, A.K. Srivastava, A.S. Virk, N. Singh, A.S. Patil, R. Viswanathan and R.K. Jain: Existence of sugarcane yellow leaf luteovirus in India. Sugar Tech, 2, 37-38 (2000).

Rao, G.P., R.K. Gaur, M. Singh, R. Viswanathan, G. Chandrasena and M.N.N. Dharamwardhaanhe: Occurrence of sugarcane yellow leaf virus in India and Sri Lanka. Proc. Intl. Soc. Sugarcane Technol., 24, 469-470 (2001).

Rao, G.P., S. Mall and C. Marcone: Recent biotechnological approaches in diagnosis and management of sugarcane phytoplasma diseases. In: Functional Plant science and Biotechnology. Recent Trends in Biotechnology and Microbiology (Eds.: R. K. Gaur et al.). Global Science Books, USA, Special issue 2, pp. 19-29 (2012).

Rao, G.P., S. Srivastava, P.S. Gupta, A. Singh, M. Singh and C. Marcone: Detection of sugarcane grassy shoot phytoplasma infecting sugarcane in India and its phylogenetic relationships to closely related phytoplasmas. Sugar Tech, 10,74-80 (2008).

Schenck, S.: Yellow leaf syndrome a new sugarcane disease. Hawaiian Sugar Planters Association. Annual Report, p.38 (1990).

Sdoodee, R.: Recent studies on white leaf and grassy shoot phytoplasma of sugarcane. Sugarcane Pathology. Virus Phytopl. Dis., 2, 235-244 (2001).

Silva, E.G., I.P. Bedendo, M.V. Casagrande and V.A. Moraes: Molecular identification and phylogenetic analysis of a group 16Srl-B phytoplasma associated with sugarcane yellow leaf syndrome in Brazil. J. Phytopathol., 157, 771-774 (2009).

Singh, V., A. Baitha and O.K. Sinha: Transmission of grassy shoot disease of sugarcane by leaf hopper (Deltociphalus vulgaris Dash \& Viraktamath). Indian J. Sugarcane Technol., 17, 60-63 (2002).

Smart, C.D., B. Schneider, C.L. Blomquist, L.J.Guerra, N.A. Harrison, U. Ahrens, K.H. Lorenz, E. Seemüller and B.C. Kirkpatrick: Phytoplasma-specific PCR primers based on sequences of the 16S-23S rRNA spacer region. Appl. Environ. Microbiol., 62, 29882993 (1996).

Soufi, Z. and E. Komor: Latent infection of asymptomatic Hawaiian sugarcane cultivars with $16 \mathrm{Srl}$ and $16 \mathrm{SrXI}$ phytoplasmas. J. Gen. Plant Pathol., 80, 255-263 (2014).

Soufi, Z., S. Sakuanrungsirikul, T. Wongwarat, T. Hamarn, S. Srisink and E. Komor: Sugarcane yellow leaf symptomatic plants in Thailand are infected by white leaf phytoplasma, not by leaf yellows phytoplasma. Australasian Plant Pathol., 42, 723-729 (2013).

Srivastava, S., V. Singh, P.S. Gupta, O.K. Sinha and A. Baitha: Nested PCR assay for detection of sugarcane grassy shoot phytoplasma in the leaf vector Deltocephalus vulgaris: A first report. Plant Pathol., 55, 25-28 (2006).

Viswanathan, R. and G.P. Rao: Disease scenario and management of major sugarcane diseases in India. Sugar Tech, 13, 336-353 (2011).

Viswanathan, R., P. Padmanaban, D. Mohanraj, SundarA. Ramesh and M.N. Premachandran: Suspected yellow leaf syndrome in sugarcane. Sugarcane Breeding Institute Newsletter., 18, 2-3 (1999).

Viswanathan, R.: Sugarcane yellow leaf syndrome in India: Incidence and effect on yield parameters. Sugarcane Int., 20, 17-23 (2002). 